Л. Г. Комиссарова. Смешанное обучение как условие формирования компетенции кооперации и сотрудничества у будущих учителей

Научная статья

УДК 37.022

DOI: $10.18101 / 2307-3330-2021-4-59-65$

\title{
СМЕШАННОЕ ОБУЧЕНИЕ КАК УСЛОВИЕ ФОРМИРОВАНИЯ КОМПЕТЕНЦИИ КООПЕРАЦИИ И СОТРУДНИЧЕСТВА У БУДУЩИХ УЧИТЕЛЕЙ
}

\author{
(C) Комиссарова Любовь Гомбоевна \\ преподаватель, \\ Бурятский государственный университет имени Доржи Банзарова \\ Россия, 670000, г. Улан-Удэ, ул. Смолина, 24a \\ luba-komissarova@mail.ru
}

\begin{abstract}
Аннотация. В данной статье рассматриваются особенности организации образовательного процесса с использованием технологий смешанного обучения. Автор уточняет понятие смешанное обучение и рассматривает в качестве оптимальной среды для развития компетенции кооперации и сотрудничества у будущих учителей в групповых проектах в условиях дистанционного обучения. В статье выделены четыре уровня интеграции элементов в модели смешанного обучения, конкретизирован термин «смешанное обучение», который рассматривается в двух основных направлениях: смешанное обучение как некий формат учебного курса, при котором в дистанционные курсы встраиваются активные методы обучения (метод проектов, групповые обсуждения, мозговой штурм, деловая игра); модель организации очного обучения с использованием распределенных информационно-образовательных ресурсов «с элементами асинхронного и синхронного дистанционного обучения».

Ключевые слова: смешанное обучение, ИКТ-технологии, дистанционное обучение, сотрудничество, кооперация.
\end{abstract}

\section{Для цитирования}

Комиссарова Л. Г. Смешанное обучение как условие формирования компетенции кооперации и сотрудничества у будущих учителей // Вестник Бурятского государственного университета. Образование. Личность. Общество. 2021. № 4. С. 59-65.

Влияние современных информационных технологий на формирование образовательной среды значительно повысилось в период пандемии COVID-19, охватившей мир в 2020 году. Информационные технологии стали, неотъемлемой частью целостного образовательного процесса, «оптимизируя учебный процесс, создавая максимально благоприятные условия» [5, с. 1364] для усвоения учебного материала в период дистанционного обучения.

Эффективной моделью при организации дистанционного обучения, которая способствовала бы плодотворному сотрудничеству и кооперации явилась смешанное обучение (blended learning) [3], главными достоинствами которого: синхронные средства коммуникации («живое» общение на платформе zoom) и асинхронные средства (самостоятельная работа обучающихся с использованием Webтехнологий) [4].

В данной статье проанализируем опыт внедрения смешанного обучения и организации образовательного процесса с использованием средств электронного обучения, на примере МДК 02.01. Основы организации внеурочной деятельности 
в области информационно-коммуникационных технологий, вводного курса программы профессионального модуля ПМ 02 Организация внеурочной деятельности обучающихся начальных классов и начальных классов компенсирующего и коррекционно-развивающего образования (Специальность 44.02.05 Коррекционная педагогика в начальном образовании, 3 курс $)^{1}[11]$ в колледже Бурятского государственного университета имени Доржи Банзарова.

Термин «смешанное обучение» (blendedlearning) впервые начали употреблять в начале 2000-х гг. в Соединенных штатах Америки, как метод обучения персонала и переподготовки кадров, позже, в 2006 г. данный термин успешно внедрили в систему среднего и высшего образования. Определение термина и особенности организации образовательного процесса с использованием смешанного обучения в достаточной степени представлены в научных трудах зарубежных ученых, таких как Пурнима Вилиатан (PurnimaValiathan), Дарлин Пейнтер (Darling Painter), Дональд Кларк (Donald Clark), Ребекка Воган Фрази (Rebecca Vaughan Frazee), Эллисон Роззетг (Allison Rossett).

В трудах Пурнима Валиатан (Purnima Valiathan) [10], Эллисон Роззетт (Allison Rossett), Ребекки Воган Фрази (Rebecca Vaughan Frazee) [7, c. 39], Дарлина Пейнтера (Darling Painter) [7, c. 39] смешанное обучение рассматривается как интегрированный образовательный процесс, в структуру которого включены разные формы организации учебной деятельности. Для эффективного обучения, для достижения высоких результатов наряду с очным обучением применяется электронное обучение с применением современных веб-технологий.

В статье М. С. Орловой рассмотрены четыре уровня интеграции элементов в модели смешанного обучения, предложенные Дональдом Кларком.

Первым, самым слабым уровнем интеграции является уровень компонентов, где элементы смешанного обучения сочетаются друг с другом и взаимозаменяемы. На данном уровне Д. Кларком выделены параллельная модель, где учебный материал представлен в разных формах, для выбора удобного варианта обучающимися и серийная модель, где учебный материал представлен модулями.

Вторым уровнем является интегрированный уровень, в котором все элементы модели смешанного обучения проектируются с учетом всех остальных. Оформление элементов модели осуществляется по единому образцу, между общими частями содержания различных элементов модели выстраиваются перекрестные ссылки и в рамках одного элемента модели обязательным является контроль в начале и в конце изучаемого материала.

Третий уровень - это уровень педагогической коммуникации. На данном уровне в процессе смешанного обучения выстраивается взаимодействие обучающих с обучающимися посредством личного общения или общения, опосредованного электронной средой.

\footnotetext{
${ }^{1}$ Коррекционная педагогика в начальном образовании: федеральный государственный образовательный стандарт среднего профессионального образования по специальности 44.02.05: утвержден приказом Министерства образования и науки Российской Федерации от 13 марта 2018 г. № 183. Зарегистрирован в Минюсте России 29 марта 2018 г. № 50568.
} 
Л. Г. Комиссарова. Смешанное обучение как условие формирования компетенции кооперации и сотрудничества у будущих учителей

Четвертый - это уровень образовательной среды, где интегрированы все элементы модели смешанного обучения. На данном уровне все элементы модели смешанного обучения гармонично (органично) включаются в образовательное пространство учебной организации [9, с. 123-124].

Учитывая тот факт, что система образования в целом функционирует в рамках образовательного пространства, то при проектировании модели смешанного обучения необходимо учитывать существующую образовательную среду и выбирать такие компоненты обучения, которые сочетаются друг с другом, дополняют, образуют методическую систему обучения сообразно образовательной среде учебной организации.

В отечественной педагогике термин «смешанное обучение» рассматривается в двух основных направлениях.

Первый подход рассматривает смешанное обучение как некий формат учебного курса, при котором в дистанционные курсы встраиваются активные методы обучения (метод проектов, групповые обсуждения, мозговой штурм, деловая игра). Основной теоретический материал представлен в рамках дистанционного курса, который предполагает самостоятельную работу учащегося; закрепление и отработка материала проходят на очных занятиях, реализуемых с использование активных методов обучения [8].

Второй подход связан с пониманием смешанного обучения как некую модель организации очного обучения с использованием распределенных информационно-образовательных ресурсов «с элементами асинхронного и синхронного дистанционного обучения» [4].

Определим особенности модели смешанного обучения в рамках последнего из перечисленных направлений рассматриваемого термина.

Согласно Ю. И. Капустину, основными, концептуальными компонентами модели смешанного обучения являются два аспекта:

- содержательный (спроектированное содержание обучения должно сочетать, с одной стороны, современные научные знания и общественные потребности в изучаемой дисциплине, с другой - личностно значимые задачи, способствующие развитию обучающегося как специалиста);

- инструментальный (процедура реализации процесса смешанного обучения должна основываться на применении технологии дистанционного обучения, включении оценочно-результатирующих блоков, описывающих критерии и показатели качества подготовки обучающихся)

Ю. И. Капустин, опираясь на модульный принцип построения содержания образования, как наибольшей степени отвечающий требованиям специфики смешанного обучения, предлагает разрабатывать образовательные программы из модулей, которая даст возможность для определения обучающимися индивидуальной образовательной «траектории». По мнению Ю. И. Капустина модуль должен иметь «законченный цикл деятельности обучающегося по освоению тематически завершенного отрезка учебного материала и развития заданного уровня компетентности». «В качестве образовательного модуля могут выступать как учебный курс в целом, так и отдельные блоки курса, если они отвечают требованию завершенности (целостности)» [4, с. 22-23]. 
При реализации смешанного обучения комплекс организационных форм обучения по модулям выстраивается на сочетаниях групповых и индивидуальных, реальных и виртуальных форм. Помимо традиционных форм, лекций, семинаров, лабораторных работ, в процессе смешанного обучения реализуется целенаправленная, интенсивная и контролируемая самостоятельная работа самого обучающегося, который может учиться в удобном для него локации, по индивидуальному расписанию, согласованному с преподавателем, комплексно используя специальные средства обучения и согласованную возможность контакта с преподавателем [4].

Методы обучения, используемые при смешанном обучении, должна обеспечивать интерактивность при взаимодействии, эффективность при освоении учебного материала и непрерывность образовательного процесса. Средства обучения выбираются согласно целям, содержанию, формам и методам обучения, с учетом их эффективности при сочетании в учебном процессе. Каждый учебный модуль должен быть оснащен специальным учебно-методическим комплексом материалов, включающий учебные пособия: хрестоматии, рабочие тетради, буклеты заданий, методические материалы, пособия по самообучению, аудио-, видеоматериалы, CD и др. [4, с. 21].

Таким образом, выбранные компоненты содержания обучения, отобранные средства, формы и методы влияют на структуру модели смешанного обучения.

В трудах М. С. Медведевой смешанное обучение определяется как трехкомпонентная система обучения в сочетании очного, дистанционного и самообучения, учебный процесс в котором реализуется через «взаимодействие между педагогом, обучающимся и интерактивными источниками информации, отражающая все присущие учебному процессу компоненты (цели, содержание, методы, организационные формы, средства обучения) функционирующие в постоянном взаимодействии друг с другом, образуя единое целое» [6, с. 13].

Трехкомпонентная система смешанного обучения представляет собой единый целостный учебно-воспитательный процесс, где непосредственная познавательная деятельность учащихся на занятиях в университете под непосредственным руководством преподавателя, тесно сочетается с дистанционным обучением с преобладанием индивидуального, реже группового видов работ, а также самообучением.

Смешанное обучение эффективнее реализовывать через интерактивную форму организации учебного процесса, где учебный материал излагается в оживленной, интерактивной форме, явно демонстрируя не только теоретический материал, но и идеи преподавателя. У студентов при активном использовании информационно-коммуникационных технологий появляется возможность «проводить сложные, опасные или дорогие опыты», «заглянуть внутрь изучаемых процессов и явлений», а также «воспитывать у себя навыки самообучения, саморефлексии и самоконтроля» $[6$, с. 13].

В концепции Е. К. Васина смешанное обучение рассматривается как «образовательный процесс, при котором изучение учебных дисциплин осуществляется по двухуровневой схеме «дистанционное изучение теоретического материала очное осуществление практической учебной деятельности в условиях образователь- 
Л. Г. Комиссарова. Смешанное обучение как условие формирования компетенции кооперации и сотрудничества у будущих учителей

ного учреждения〉 и на каждом уровне активно внедряются в учебный процесс специализированные электронные образовательные ресурсы, которым передается часть функций обучающего. Тем самым, модель смешанного обучения реализуется на основе функционирования деятельностного треугольника «обучающийся - учитель ЭОР (электронные образовательные ресурсы)» [2, с. 46].

На сегодня, смешанное обучение становится неотъемлемой частью образовательного процесса и обладает рядом преимуществ, которые удовлетворяют требования современного процесса модернизации в сфере профессионального образования.

Таким образом, смешанное обучение (blendedlearning) позволяет организовать образовательный процесс в сочетании традиционной формы обучения с дистанционной, с применением информационно-коммуникационных технологий, Интернет-ресурсов в благоприятной образовательной информационной среде, с выстраиванием комфортной коммуникативной структуры, с сохранением живого общения между всеми участниками образовательного процесса. При этом у каждого обучающегося появляется возможность непрерывно обучаться по индивидуальной «траектории» развития, выбирая объем и уровни сложности изучаемого материала в соответствии со своим темпом, сначала восполняя пробелы в понимании материала, затем углубляя свои знания в зависимости от своих интересов, потребностей и способности. При смешанном обучении у преподавателя появляется возможность быстро и с наименьшими трудозатратами контролировать усвоение изученного материала и предоставлять обучающимся отчет о результатах его изучения теоретического материала, тем самым обеспечивая эффективную обратную связь.

При проектировании образовательного процесса по дисциплине «Основы организации внеурочной деятельности в области информационно-коммуникационных технологий» в период дистанционного обучения мы учитывали существующую образовательную среду и выбрали смешанное обучение с использованием ИКТ-технологий, так как данная модель наибольшей степени соответствовала требованиям программы.

Смешанная форма обучения реализовывалась нами в сочетании дистанционного обучения посредством «живого» общения через платформу zoот и обучение, посредством использования обучающей системе Moodle и чатов. При организации образовательного процесса с использованием смешанного обучения в первую очередь нами был распределен учебный материал на модули, изучаемые посредством «живого» общения и модули, изучаемые самостоятельно в системе Moodle, а также были разработаны задания для индивидуального изучения и задания для групповой проработки в чатах. При грамотном распределении учебного материала, у студентов появляется возможность самостоятельно изучать учебный материал, опираясь на свой имеющийся опыт и знания, и обучаться, ориентируясь на индивидуальную траекторию своего развития. Преподаватель может контролировать деятельность студентов, при этом выполняя функции консультанта.

Студенты, посещая «живые» занятия на платформе zoom совместно с преподавателем, где занятия проводились в форме лекционных занятий с демонстрацией презентаций, осваивали основной модуль. Для углубления знаний по дисциплине, на практических занятиях студенты, в системе Moodle, выполняли проекты на заданные 
темы, в режиме онлайн. После выполнения творческих, проектных заданий были организованы круглые столы по защите проектов. В рамках данного курса были реализованы групповые проекты студентов на темы: «Планирование работы кружка по ИКТ «Первые шаги в мире ИКТ», «Методическая разработка внеклассного занятия с использованием ИКТ», «Методическая разработка олимпиадных заданий для младших школьников».

Совместные групповые работы студентов над проектным заданием были реализованы в системе управления обучением Moodle с применением технологии вики. С помощью технологии вики студенты легко и быстро создали паспорта проектов, в виде таблицы, у всех была возможность внести изменения, либо расширить и обновить материал. В онлайн формате попытались раскрыть и описать особенности организации внеурочной деятельности с использованием ИКТ. Так как, данный вид деятельности индивидуальный, то у каждого студента была возможность работать в системе в любое удобное для него время, но при этом при выполнении проектных заданий был установлен крайний срок выполнения задания. Такая форма работы обеспечила нам асинхронную коммуникацию, гибкость в изучении материала и творческий подход.

Данная технология способствует формированию у студентов умения работать в команде, искать пути решения, понимать и выполнять разные роли для успешного решения комплексных задач, что приводит к продуктивному сотрудничеству и кооперации.

При работе с данным инструментом у преподавателя появляется возможность контролировать самостоятельную деятельность студентов, видеть появившиеся изменения в документе, а также отслеживать, кто принимал участие в создании общего документа, а кто нет. В комментариях к заданиям есть возможность обсуждать идеи, вносить свои предложения и поправки, а также можно отформатировать текст.

Обучение с применением технологии вики позволяет учить студентов сотрудничеству, совместной работе в команде, получать знания и информации совместными усилиями, вместе и сообща [5, с. 1366]. Работа в системе Moodle с применением технологии вики позволяет активизировать работу студентов, где они получают знания не пассивно, а непосредственно принимая активное участие в совместной учебной деятельности.

Все эти возможности позволяют эффективно организовать процесс обучения.

\section{Лuтература}

1. Андреев А. В., Андреева С. В, Доценко И. Б. Практика электронного обучения с использованием Moodle. Таганрог: Изд-во ТТИ ЮФУ, 2008. 146 с. Текст: непосредственный.

2. Васин Е. К. О смешанном обучении на основе функционирования деятельностного треугольника // Современные исследования социальных проблем. Modern Researchof Social Problems. 2016. № 1(57). C. 39-54. URL: https://cyberleninka.ru/article/n/o-smeshannom-obucheniina-osnove-funktsionirovaniya-deyatelnostnogo-treugolnika/viewer (дата обращения: 18.05.2021). Текст: электронный.

3. Волкова О. А. Организация самостоятельной работы студентов колледжа на основе системы дистанционного обучения moodle: модель смешанного обучения: Информатизация образования: теория и практика: сборник материалов международной научно-практической конференции / под общей редакцией М. П. Лапчика. Омск, 2014. С. 196-198. Текст: непосредственный. 
Л. Г. Комиссарова. Смешанное обучение как условие формирования компетенции кооперации и сотрудничества у будущих учителей

4. Капустин Ю. И. Педагогические и организационные условия эффективного сочетания очного обучения и применения технологий дистанционного образования: автореферат диссертации на соискание ученой степени доктора педагогических наук. Москва, 2007. 42 с. Текст: непосредственный.

5. Краснова Т. И. Вики технологии в организации самостоятельной работы на платформе Moodle // Молодой ученый. 2015. № 11. С. 1364-1368. Текст: непосредственный.

6. Медведева М. С. Формирование готовности будущих учителей к работе в условиях смешанного обучения: автореферат диссертации на соискание ученой степени кандидата педагогических наук. Нижний Новгород, 2015. 31 с. Текст: непосредственный.

7. Медведева М. С. Подготовка будущих учителей к работе в условиях смешанного обучения // Научный поиск. 2015. № 1. С. 39-47. Текст: непосредственный.

8. Мохова М. Н. Активные методы в смешанном обучении в системе дополнительного педагогического образования: автореферат диссертации на соискание ученой степени кандидата педагогических наук. Москва, 2005. 24 с. Текст: непосредственный.

9. Орлова М. С. Модель смешанного обучения и их применение при обучении программированию // Вестник Московского городского педагогического университета. Сер.: Информатика и информатизация образования. Московский городской педагогический университет. 2008. № 11. С. 122-124. Текст: непосредственный.

10. Purnima Valiathan. Blended Learning Models. URL: https://purnima-valiathan.com/wpcontent/uploads/2015/09/Blended-Learning-Models-2002-ASTD.pdf (date of the application: 20.10.2021).

Статья поступила в редакцию 02.10.2021; одобрена после рецензирования 13.10.2021; принята к публикащии 15.12.2021.

\title{
BLENDED LEARNING AS A CONDITION FOR THE FORMATION OF COOPERATION AND INTERACTION COMPETENCE OF FUTURE TEACHERS
}

\author{
Lyubov G. Komissarova \\ Lecturer, \\ Dorzhi Banzarov Buryat State University \\ 24 a Smolina St., Ulan-Ude, 670000, Russia \\ Luba-komissarova@mail.ru
}

This article examines the features of the educational process using blended learning technologies. The author clarifies the concept of blended learning and considers it as the optimal environment for the development of cooperation competence and collaboration of future teachers in group projects in a distance learning environment. The article highlighted four levels of integration of elements in the blended learning model, "blended learning" term was specified, which is considered in two main directions: blended learning as a kind of training course format, in which active teaching methods are built into distance courses (project method, group discussions, brainstorming, business game); a model of organizing full-time learning using distributed information and educational resources «with elements of asynchronous and synchronous distance learning»».

Keywords: blended learning, ICT technologies, distance learning, cooperation, collaboration.

The article was submitted 02.10.2021; approved after reviewing 13.10.2021; accepted for publication 15.12.2021. 